\title{
Investigating Warehousing Operations from an Integrated Supply-Chain and Transportation Approach
}

\author{
Sushant Siddharth Wanjari
}

\begin{abstract}
Transportation a primary step in the supply chain of goods. The responsive time between the parts of this chain may critically affect the duration of the processes. By accounting on an integrated system, warehouses can increase the accuracy and reliability of the processes. This paper analyzes the feasibility of integrated transportation and warehousing platforms from two points of view: infrastructure (e.g. physical place, geographical location) and organizational perspective (e.g. software, data, models). This paper contributes to fill the gap between practitioners and researchers about the needs of both systems. This paper found that transportation and warehousing are two inherently linked systems. However, the current practice lacks substantial improvements in data collection and modeling of these systems. Future directions point towards the use of big data and the implementation of econometric concepts (i.e. choice models), together with a spatial understanding of the impact of warehousing locations (i.e. accessibility concept) in transport costs. E-commerce, big data, and autonomous driving are the future challenges to integrating these two systems of warehousing and transportation. Finally, with the current pandemic of COVID-19, improving freight services is becoming a basic need. This paper contributes to a better understanding of the needs of integrating transportation and warehousing in the current challenging times.
\end{abstract}

Index Terms - Supply Chain, Warehousing, Transportation Models, Cross-Docking.

\section{INTRODUCTION}

Modeling dynamics of transportation is a crucial objective considering the current times. Freight, as the movement of goods, plays an important role in the economy. The faster the products arrive at the client, the faster the economy will internalize the revenues. Therefore, optimizing the supply chain as a productivity chain is a common objective of transportation and warehousing sectors.

Integrating warehousing and transportation systems can help to decrease the need for stock, overstock, and lack of real-time information [25]. The availability of data, and the use of it, is a major challenge for companies when real-time information is feasible. Therefore, researchers should work on the development of tools to process this data as feeders of informative tools for further decisions. Some researchers have discussed tools to manage warehousing data [39]. However, the extent to which those tools enable a more efficient link between transportation and warehousing operations is still unclear.

Cross-docking has been in the market of warehousing for a long time, where goods are maintained at the warehouse for short or no-time. Cross-docking is an example of transportation and warehousing integration, as a logistics concept, it integrates intermediate nodes into a transportation network so that shipments are consolidated to full truckloads and economies of transportation are realized [34]. The main point of cross-docking is the limited use of a temporary storage area where shipments are moved from the unloading trucks to the area respective outbound destinations. However, there are negative effects when it comes to transportation economies, e.g. long delivery times due to routing of the fully loaded truck. At the same time, cross-docking improves the supply chain avoiding wrong orders and mistakes in production (i.e. the Bullwhip Effect) [22]. Integrated realtime information is crucial in this multidimensional concept of cross-docking.

Several factors affect the integration between warehousing and transportation systems. For example, location is an important factor to optimize the total system: warehousing transportation. In the early 80s, [28] explored the interdependence between location and vehicle routing as warehouse location-routing problem to minimize the total system costs (warehousing and transportation). And more recently, [29] in a more empirical approach, analyzed via computational experimentation to strategically located distribution centers of specific goods based on the location of stores and final customers. Geographic distribution of warehousing has turned into the main factor to consider in the supply chain given the phenomenon 'logistic sprawl', which covers the scattered distribution of warehouses [10]. And, choice models can help to optimize the selection of warehouses based on several factors, such as availability of storage place, time loading, and unloading, access by road, distance, etc.

This paper analyzes the feasibility of integrated transportation and warehousing platforms from three perspectives: methods, data, and geographical scope. The modeling part includes the optimization of locations and modes used in transportation. The data availability part includes the different data collection methods, such as surveys, big data, to inform the decision-makers. This paper contributes to fill the gap between practitioners and researchers about the needs in both systems. The novelty of this paper refers to the discussion of relevant concepts (choice modeling, accessibility, last-mile) to identify the needs and new trends of an integrated transportation-warehousing operation. The remaining of this paper is structured as follows: Section 2 presents the case study to analyze based on secondary data. Section 3 discusses the data and methods used in practice to approach the integration of transportation 
and warehousing. Section 4 presents a systematic analysis of the research gaps, while Section 5 concludes the paper and provides the final remarks.

\section{CONCEPTUAL FRAMEWORK}

\section{A. Management and Operation}

Figure 1 shows an integrated framework of transportation and warehousing including several actors. Firstly, Fig. 1 shows the transportation costs and system management (as operational costs, modeling, and needs). There is a need to bridge the knowledge and common terms of gaps between practitioners and researchers. See for an overview of warehousing operations [15], where the operations of warehousing are organized as the basic functions (i.e. receiving, storage, packing, and shipping). Secondly, Fig. 1 also shows an intermediate link where location and routing are important challenges. And, practices as cross-docking help to integrate the two systems (transportation and warehousing).

Thirdly, we have the operations and systems of warehousing. At this point, the management role needs to make informed decisions, and the information may come from reliable sources, as models and data. Implementation of modern project management philosophies might bring efficiency to these systems. Management philosophies over time have demonstrated the pros and cons. For example, the Just-in-time, promoted and implemented as Agile methodology refers to the ability to release marketable pieces of a product after each iteration, promoting communication and reducing waste. Voluntarily, members of the team pick their tasks. With the same approach, warehousingtransportation systems could be oriented to release a solution always usable to the client (i.e. a place to pick the goods, a place to store over a variety of options). Members of a network would feed the system with real-time data (easy communication) that will facilitate options to the customers and companies.

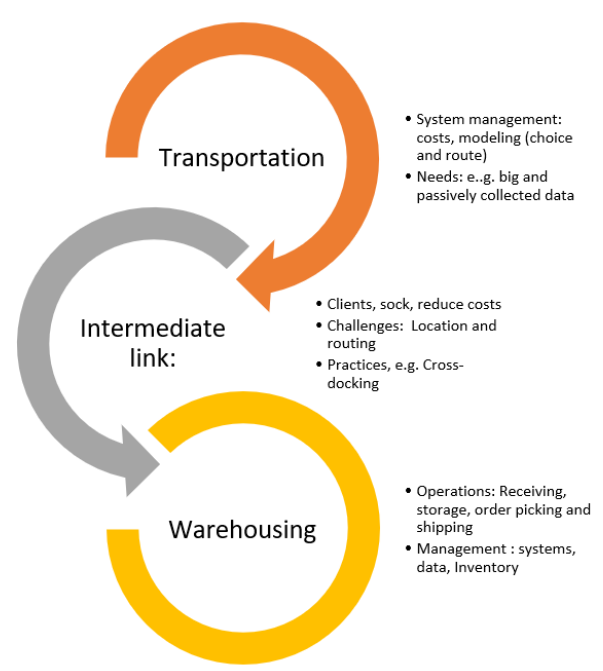

Fig. 1. Integrated Framework of the supply chain for Transportation and Warehousing.

\section{STATE OF THE ART: DATA AND METHODS}

\section{A. Data and Methods used in Practice}

The ability to collect data is the foundation for accurate estimates in transport systems. Several methods can be implemented to collect information on freight transport: surveys, GPS data either actively or passively collected, interviews.

Surveys: as a data collection method, surveys are widely used in travel behavior as collection methods to implement an econometric approach, which is transferable to freight models. For example, stated preference surveys are based on hypothetical scenarios where (i.e. cost and time) attributes of alternatives are modified. [18] analyzed SP-values of time and reliability for freight transport in the Netherlands based on a survey among 800 respondents. The estimation of the value of time from stated preference surveys indicates the amount of money that operators or users are willing to charge or pay for a feature when transporting.

Big data: or passively collected data can be used to estimate robust choice models for freight. Currently, cloud computing and the internet of things are completely covering the economic market. The availability of big data to feed any field of economy, such as transportation, is imminent. [25] conducted an empirical study of the integration of warehouse and transportation. [24] provided an example of case warehouse schedules. advantage of using big data is having scalable analysis go beyond. For example, adding new services. Last-mile studies, smart cities, and new mobility are a high priority and freight directly impacted by those trends.

The availability of real-time information is possible via the concept of Virtual Warehouse (VM). And, at the same time, this concept would make it possible to integrate the real-time information from both warehouse and transport operators. The virtual warehouse (VW) is a state of real-time global visibility for logistics assets such as inventory and vehicles [21]. So far, there is no empirical research about the integration of these two components. The VM requires the availability of mobile-phone applications with global positioning, geographic information, and automatic identification. Similarly, GPS based mobility collectors can detect the positioning of vehicles and upload this information to a server. A mobility collector is an algorithm designed to automatically or semi-automatically track trips of the users. Several studies have collected, and some of them have also analyzed, GPS data with or without mobility collectors, for an overview see [31].

Recommendation: Further, the use of technology for lastmile in freight is outstanding. Further, understanding the needs of providers and customers will make the distribution more efficient. The use of more accurate data will improve this understanding into a deeper knowledge. Often, last-mile of deliveries can be achieved with more sustainable modes, i.e. bicycles or scooters. While reducing the stock and warehousing costs.

\section{B. Methods and Models used in Practice}

Discrete choice models are very popular in transport research to analyze travel behavior. These models are based on random utility theory [26]. Any behavioral process is informed by people's perceptions and beliefs based on the 
available information and influenced by effect, attitudes, motives, and preferences [4]. The information about available alternatives is contained in observable elements, whereas the attitudes, motives, and preferences form unobservable or latent elements. In this context, latent means potentially existing but not evident or realized. Choice models can be implemented in freight and warehousing from at least two structures: mode choice and location choice. Choice models have been around for decades, but rarely implemented in freight transport.

Regarding mode choice, the issues in modeling freight transport at the national level are multidimensional and diverse. Mode choice models try to explain the allocation of a given total freight transport demand to these modes [11]. Several factors influence the performance of freight models, such as mode (air, rail, road), vehicle type (wagon, vessel, etc.) or geographical scope (national or international). for some countries, there is a national freight model. When it comes to location choice, some researchers have analyzed the factors influencing the choice from a geographical perspective [19], showing the impact of spatial decentralization of urban freight locations. They found that for warehouses the most influential factors are local market, labor, and seaport/intermodal terminal proximity. They implemented a choice set design (means the alternatives available), location attributes and travel time measurements (i.e. land prices, population and employment densities, travel time to the nearest local market, travel time to the nearest trade node, and labor force access. They estimated multinomial logit models, which are widely known in statistics in general.

Further, [30] developed a location choice model for logistics facilities, applying the framework of the discrete choice models. The models show heterogeneity in the factors for location choice by facility size and suggest a strong influence of shipping origins and destinations for each facility's choice of location.

Recommendation: In summary, understanding the influential factors and being able to generate this information from (public or funded) data is crucial. For example, being able to measure accessibility, travel times, and distances from the warehouse location. The next section presents a close look at the accessibility as a concept, which is more common in studies of passenger travel.

\section{Warehousing Accessibility: A concept to develop further}

Accessibility is the common ground concept for both locations and transportation of goods or people. Therefore, the concept of accessibility presents substantial advantages to the freight and warehousing field. Defining accessibility as the easiness to achieve a destination or group of destinations. Geurs and van Wee (2004) distinguished four components of accessibility: a land-use component, a transport component, a temporal component, and an individual component. In the context of freight, these components can be explained as follows:

- the land-use component means the location of the logistics firms and the customers.

- the temporal component refers to the time of the distribution trips, i.e. peak, off-peak.
- the individual components refer to the customer demographics.

- and the transport component refers to the transport network, i.e. railways, roadways, etc.

These factors are interconnected and operate simultaneously or discretely since accessibility measures vary from contour, infrastructure based, potential accessibility among others. For example, research shows that the land-use component operates with the transport component. When it comes to warehousing, accessibility produces direct impacts on location. [6] concluded that in the U.S. the expansion of warehousing is strongly correlated with places with superior accessibility in the nation's air and highway transportation networks, and less correlated with rail networks (transport component). Similarly, central cities of urban areas have experienced a declining share of logistics firms [17].

Further, [20] provide a case study in health care logistics, where Geographic Information Systems (GIS) were used to identify the location-allocation warehouse potential. They found that the efficiency of the delivery does not increase substantially when the number of warehouses increases.

Accessibility is a very broad concept that can be very useful for freight and warehousing studies. Accessibility includes a wide variety of measures that accommodate weights (i.e. population, jobs), probabilities (distance decay functions), and cumulative measures. [7] analyzed transport terminal influence through accessibility analysis and proposed a freight transport trip-chain index that considers the activities available in the zone. And, [23] analyzed the performance of the intermodal freight network by comparing accessibility measures based on the highway network and the intermodal network. Consistent with [36] who analyzed the performance of the intermodal freight network by comparing Gravity-type accessibilities and shipping impedance decay effects.

In the Asian context, transport infrastructure has been analyzed based on accessibility measures, and it was found that changes in residential areas induce the development of transport infrastructure [2]. However, the extent to which changes in warehousing or freight hubs attract the development of transportation infrastructure in those countries deserves attention.

Finally, as a closing remark on the accessibility section, it is important to point out the node-place concept. Similar to the concept of place and node that Luca Bertolini defined for train stations (Bertolini, 1996), a warehouse is a location with a role as a place to store, move, pick and drop-off products. Also have a node role that depends on its position in the network.

Recommendation: This section highlights that accessibility currently deserves attention to integrate transportation and warehouse research. Also, there is an unbalanced amount of research from specific regions of the world. To analyze network performance and accessibility of warehouses availability of secondary geographic data related to freight transport and its components (warehousing, transport operations) is a constrain in some countries. For example, OpenStreetMap offers public information but with limited or no details about locations of warehousing in Australia. 


\section{Last-Mile Concept}

If With e-commerce, the number of online orders is increasing considerably. Future directions point towards the use of technology (i.e. electric vehicles, autonomous vehicles) to improve the last-mile delivery. Some researchers have studied the business model of Drone-based delivery by analyzing customer's attitudes towards technology and products [14]. The use of autonomous vehicles would increase sustainability and reduce the warehousing costs of the products. Similarly, [8] show possible last-mile solutions in Europe as electric bikes, cargo bikes, and electric vehicles. In this part, urban form is a factor to control since key influential variables are roadway density and service-area-towarehouse distance [38]. And research from Singapore shows that sharing the last mile in orders can significantly reduce the delivery costs [16], this is called collaborative carrier.

The concern of the last-mile affects the location of warehouses since more distant or regional warehouses will be served by the last-mile services instead of having the warehouse closer to population centers.

\section{SyStEMATIC ANALYSIS OF RESEARCH GAP}

This section systematically summarizes the research studies discussed in this paper. Table 1 shows a summary of the research dimensions and methods discussed in this paper by country and empirical approach. As we can observe, most of the research done in this field belongs to either warehousing or freight, while none of these papers analyzed an integrated framework. Further, most of the research has been done in the USA or Europe, being Asian countries left behind. And, just a few papers implemented choice models as an analytical framework.

TABLE 1: SUMMARY OF RESEARCH METHODS

\begin{tabular}{|c|c|c|c|c|}
\hline Paper/study & Dimension & $\begin{array}{c}\text { Country } \\
\text { /continent }\end{array}$ & $\begin{array}{c}\text { Method } \\
\text { (empirical } \\
\text { or review) } \\
\end{array}$ & $\begin{array}{l}\text { Empirical } \\
\text { approach }\end{array}$ \\
\hline [8] & Last mile & Europe & Review & \\
\hline [30] & $\begin{array}{l}\text { Warehouse } \\
\text { Location }\end{array}$ & Asia & Modeling & $\begin{array}{l}\text { Discrete } \\
\text { choice }\end{array}$ \\
\hline [19] & Warehouse & $\begin{array}{l}\text { USA (Los } \\
\text { Angeles) }\end{array}$ & Modeling & $\begin{array}{l}\text { Location } \\
\text { choice }\end{array}$ \\
\hline [6] & Warehouse & USA & Modeling & $\begin{array}{c}\text { Spatial } \\
\text { analysis }\end{array}$ \\
\hline [21] & $\begin{array}{l}\text { Warehouse } \\
\text { (virtual) }\end{array}$ & USA & $\begin{array}{l}\text { Static, } \\
\text { dynamic } \\
\text { model }\end{array}$ & \\
\hline [38] & $\begin{array}{l}\text { Last mile, } \\
\text { Warehouse } \\
\text { location, } \\
\text { CO2 }\end{array}$ & USA & Modeling & $\begin{array}{c}\text { Regression } \\
\text { analysis }\end{array}$ \\
\hline [16] & Last mile, & Singapore & Modeling & $\begin{array}{l}\text { Double } \\
\text { auction }\end{array}$ \\
\hline [11] & Freight & Europe & Modeling & \\
\hline$[28]$ & $\begin{array}{c}\text { Warehouse } \\
\text { location }\end{array}$ & & Modeling & \\
\hline$[18]$ & Freight & Europe & Review & \\
\hline$[10]$ & $\begin{array}{c}\text { Warehouse } \\
\text { location }\end{array}$ & USA & Modeling & $\begin{array}{c}\text { Spatial } \\
\text { analysis }\end{array}$ \\
\hline Carteni & Freight & Italy & Accessibility & $\begin{array}{c}\text { Spatial } \\
\text { analysis }\end{array}$ \\
\hline [23] & Freight & USA & Accessibility & $\begin{array}{c}\text { Spatial } \\
\text { analysis }\end{array}$ \\
\hline$[36]$ & Freight & USA & Accessibility & $\begin{array}{c}\text { Spatial } \\
\text { analysis }\end{array}$ \\
\hline
\end{tabular}

And, another concern of the freight analysis is scalability. Studies focused on big hubs (i.e. terminals, ports) are not scalable to local or regional warehouses. A warehouse is a place to store products. While a terminal is mostly a transfer place. Therefore, more research in the unit of the warehouse is needed.

Considering the gap between European countries and Asian, the next section analyzes the opportunities of warehousing-transportation research in the Australian context.

\section{A CASE STUDY: AUSTRALIAN FREIGHT TRANSPORT}

The transport and logistics sector are a major economic sector worldwide. Particularly, in Australia has an estimated annual revenue of $\$ 102.87$ billion, with an operating profit of $\$ 10.14$ billion in 2018 [9]. In Australia, between 2006 and 2016, the domestic freight task grew by $50 \%$ while our population grew by $18 \%$ over the same period. Further, growth in Asia and an increasingly globalized economy means the volume and value of Australia's trade is increasing. [13]. The urban freight is a challenge for this economy since land-use planning is crucial, given the urban sprawl faced by the cities nowadays. Transportation research should focus on solving bottlenecks and reduce congestion around ports and ground transport freight. While rail mode share in freight transport has remained low, this is a new opportunity to explore.

An extensive Australian review about the role of transportation in the logistics chain, [37] highlighted the important and multidimensional interdependent relation between transport and logistics development. The paper approaches interesting topics such as E-commerce (ebusiness) as an impactful trend, being the cost of transportation one-third of the logistic cost.

As we can observe from the literature review, there is an imminent need to integrate warehousing and freight transportation conceptually and operationally. Among other elements, the potential for integration warehouse and transport services relies on the availability of accurate databases in a longitudinal and granulated structure. For example, smartphone GPS based data.

\section{A. A Note on Current Situation}

This paper is being written during the COVID-19 pandemic. With the current limitations of social distancing, and the inability to move freely, communities are starting to change mobility patterns, doing more e-commerce, online grocery shopping, frequent deliveries, using more the car instead of public transport. At the same time, the increase in deliveries and car use exacerbates traffic congestion. All these components make more important the plan efficiently the supply chain and distribution of products.

Google provides mobility reports to measure the impact of COVID-19 on the mobility of communities around the world [12]. This data enables a fair comparison of statistics and big data from different countries, divided by cities or states. The places identified are:

- Retail and recreation: restaurants, cafés, shopping centers, theme parks, museums, libraries, and cinemas.

- Supermarket and pharmacy: supermarkets, food 
warehouses, farmers markets, specialty food shops and pharmacies.

- Park: national parks, public beaches, marinas, dog parks, plazas, and public gardens.

- Public transport hubs, such as underground, bus and train stations.

- Places of work.

- Places of residence.

When comparing Australia and U.S.A., the results of these reports show that mobility trends around public transport hubs experience a reduction of $21 \%$ compared to a baseline (January-February 2020). Further, the report shows similar patterns in terms of reduction of mobility trends, except for places like national parks, public beaches, marinas, dog parks, plazas, and public gardens. Whereas, some places experience an increase in movements around residential areas.

The Australian government [13] presents statistics of freight transport. In their report, the audit indicates that the rapid growth in micro-freight activity has also led to challenges for storing and warehousing. Logistics companies increasingly look for strategically placed land to ensure quick and effective delivery from warehouses to key centers of demand, but this land is often scarce. Then, logistics companies are forced to move further away from their key demand and supply centers. Figure 2 shows an increase in vehicle-kilometer driven by light commercial vehicles. An increase in deliveries by light commercial vehicles is contributing to road and kerbside congestion, particularly in inner urban areas.

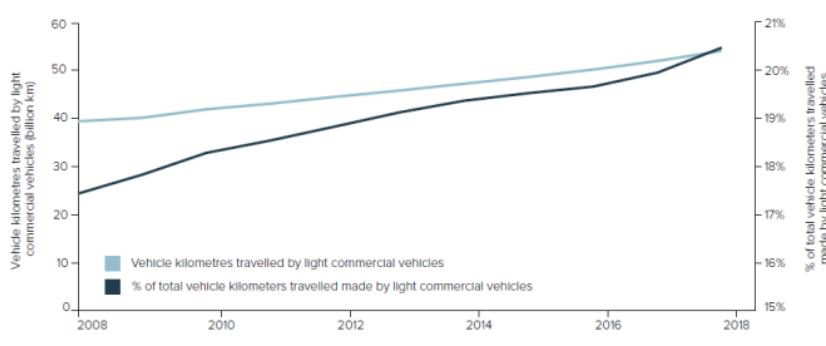

Fig. 2. Vehicle Kilometers travelled by light commercial vehicles grew over the last decade.

B. Exploration of secondary data for an Australian case study

When it comes to gathering secondary data, the following sources were found:

$>$ Information available in OpenStreetMaps [27] contains:

- Types of transport locations, divided as bus stops, bus stations, terminals.

- Geographical Coordinates.

$>$ The website of the Australian Government, Department of Infrastructure, Transport and Regional Development, and Communications includes transport statistics.

$>$ The Australian Bureau of Statistics (ABS) collections of transport [1]: unfortunately, this data is not discussed in the present paper since they are considered outdated.

$>$ Road Freight Movements, Australia [32].

$>$ Measuring the impacts of COVID-19 [33]: this is a valuable source of information since the current pandemic is significantly affecting freight transport. The study of changes and trends in shopping trips, mode use per trip purpose and activities around warehouses will contribute to improving the network service.

\section{CONCLUSION AND FINAL REMARKS}

This paper analyzed the integration of warehousing and transportation. This paper discusses the pros and cons of different methodologies and highlights the needs and future steps of research towards integrating warehouse and transportation conceptually and operationally. The innovation of this paper belongs to the examination of a conceptual approach to integrating the operations between warehouses and transportation systems. The paper emphasizes on specific aspects (i.e. data, modeling, geographical locations) that will contribute to conceptually integrate the operations between the warehouses and transportation system. By filling this research gap, the freight sector will have more efficient processes.

Particularly, as we could examine, practices as crossdocking optimize both systems, as reducing the storage time combined with on-demand transportation. However, issues such as 'last-mile' still lack attention in several countries.

Transport-related research is becoming increasingly important, due to the urgent need to diminish the emission of gases that drive and accelerate climate change. This has led to the worldwide design and implementation of strategies, policies, and measures to entice consumers to reduce their car use. However, these initiatives are not as successful as they could be as the field faces a major hurdle.

The integration of transportation and warehousing concepts is complex and multidimensional as it involves several factors. First, firms need to approach strategic locations and distributions systems. To do so, decisionmakers and project planners need to gather reliable information. As described in the present paper, the research to integrate the concepts warehousing and transportation need sophisticated data sources to accomplish robust models. For example, the use of GPS data, big data, location apps, and any other source of location sharing to accurately represent the movements. Connected vehicles currently share information about the position, and there are many other sources of positioning data to be integrated, visualized, and processed to model freight, distribution of products and location of firms. In the U.S.A some firms gather and commercialize big data from trucks, cellular towers, in-vehicle navigation GPS devices and opt-in app to develop travel demand models, see for example [35]. In Australia, several private companies collect and analyze big data for machine learning and modeling.

Big data sources contain spatiotemporal patterns, but their obvious potential remains unexplored. However, to break new ground, we first need to develop new, highly sophisticated methods of collection, processing, and validation of big data for use in transport research. Currently, there is still a reliance on cross-sectional surveys conducted among small samples.

This paper found out the gaps in research regarding transportation and warehousing by transferring a few concepts of passenger transport to freight context. The main identified gaps are aggregated as data and models. While, a geographical asymmetry was identified, by exposing 
different studies and the country/continent case study. This is the first paper that approaches transportation (freight) and warehousing using a multidimensional concept of research methods, data, and geographical scope. As future research, an empirical approach can include both descriptive and explorative analyses over the case study. For example, an analysis of GIS data, accessibility (considering speeds, travel times, curfews, and operational constraints) and freight demand over the hubs and warehouses of Australia. This paper highlights the next steps to follow towards redesigning an integrated concept of warehousing and transportation. As future research, the impact of the current pandemic COVID19 on the operations of warehouses should be analyzed.

\section{REFERENCES}

[1] (ABS), A.B.O.S. 2020. Transport [Online]. Available: https://www.bitre.gov.au/statistics/external/transport [Accessed July 2020].J. U. Duncombe, "Infrared navigation —Part I: An assessment of feasibility," IEEE Trans. Electron Devices, vol. ED-11, pp. 34-39, Jan. 1959.

[2] ANDANI, I. G. A., LA PAIX PUELLO, L. \& GEURS, K. T. 2019. Effects of toll road construction on local road projects in Indonesia. Journal of Transport and Land Use, 12, 179-199.

[3] BEN-AKIVA, M. \& LERMAN, S. R. 1985. Discrete Choice Analysis, Cambridge, MA, MIT Press.

[4] BEN-AKIVA, M., MCFADDEN, D., GÄRLING, T., GOPINATH, D., WALKER, J. L., BOLDUC, D.,

[5] BÖRSCH-SUPAN, A., DELQUIÉ, P., LARICHEV, O., MORIKAWA, T., POLYDOROPOULOU, A. \& RAO, V. 1999 Extended Framework for Modeling Choice Behaviour. Marketing Letters, 10, 187-203.

[6] BOWEN, J. T. 2008. Moving places: the geography of warehousing in the US. Journal of Transport Geography, 16, 379-387.

[7] CARTENİ, A. 2014. Accessibility Indicators for Freight Transport Terminals. Arabian Journal for Science and Engineering, 39, 76477660.

[8] CLAUSEN, U., GEIGER, C. \& PÖTING, M. 2016. Hands-on Testing of Last Mile Concepts. Transportation Research Procedia, 14, 15331542.

[9] COMMiTTEE, A. I. A. S. 2020. Transport and Logistics [Online]. [Accessed].

[10] DABLANC, L., OGILVIE, S. \& GOODCHILD, A. 2014. Logistics Sprawl: Differential Warehousing Development Patterns in Los Angeles, California, and Seattle, Washington. Transportation Research Record, 2410, 105-112.

[11] DE JONG, G. 2014. 6 - Mode Choice Models. In: TAVASSZY, L. \& DE JONG, G. (eds.) Modelling Freight Transport. Oxford: Elsevier.

[12] GOOGLE. 2020. See how your community is moving around differently due to COVID-19 [Online]. Available: https://www.google.com/covid19/mobility/ [Accessed July 2020].

[13] GOVERNMENT, A. I. 2019. Australian Infrastructure Audit: Transport

[14] GRAMATIKOV, S., KITANOVSKI, I., MISHKOVSKI, I. \& JOVANOVIK, M. 2019. Last Mile Delivery with Autonomous Vehicles: Fiction or Reality?

[15] GU, J., GOETSCHALCKX, M. \& MCGINNIS, L. F. 2007. Research on warehouse operation: A comprehensive review. European Journal of Operational Research, 177, 1-21.

[16] HANDOKO, S. D. \& LAU, H. C. 2016. Enabling Carrier Collaboration via Order Sharing Double Auction: A Singapore Urban Logistics Perspective. Transportation Research Procedia, 12, 777-786.

[17] HOLL, A. \& MARIOTTI, I. 2018. The Geography of Logistics Firm Location: The Role of Accessibility. Networks and Spatial Economics, $18,337-361$.

[18] JONG, G. D., TAVASSZY, L., BATES, J., GRøNLAND, S. E., HUBER, S., KLEVEN, O., LANGE, P., OTTEMÖLLER, O. \& SCHMORAK, N. 2016. The issues in modelling freight transport at the national level. Case Studies on Transport Policy, 4, 13-21.

[19] KANG, S. 2018. Warehouse location choice: A case study in Los Angeles, CA. Journal of Transport Geography, 102297.

[20] KOTAVAARA, O., POHJOSENPERÄ, T., JUGA, J. \& RUSANEN, J. 2017. Accessibility in designing centralized warehousing: Case of health care logistics in Northern Finland. Applied Geography, 84, 8392 .
[21] LANDERS, T. L., COLE, M. H., WALKER, B. \& KIRK, R. W. 2000. The virtual warehousing concepts. Transportation Research Part E: Logistics and Transportation Review, 36, 115-126.

[22] LEE, H. L., PADMANABHAN, V. \& WHANG, S. 1997. Information Distortion in a Supply Chain: The Bullwhip Effect. Management Science, 43, 546-558.

[23] LIM, H. \& THILL, J. C. 2008. Intermodal freight transportation and regional accessibility in the United States. Environment and Planning A, 40, 2006-2025

[24] LUO, H., YANG, X. \& WANG, K. 2019. Synchronized scheduling of make to order plant and cross-docking warehouse. Computers \& Industrial Engineering, 138, 106108.

[25] MASON, S. J., MAURICIO RIBERA, P., FARRIS, J. A. \& KIRK, R G. 2003. Integrating the warehousing and transportation functions of the supply chain. Transportation Research Part E: Logistics and Transportation Review, 39, 141-159.

[26] MCFADDEN, D. 1981. Econometric Models of Probabilistic Choice. In: MANSKI, C. F. \& MCFADDEN, D. (eds.) Structural analysis of discrete data with economic applications. Cambridge, MA: MIT Press.

[27] OPENSTREETMAP. 2020. Shapefiles for Geographic Information Systems (GIS) [Online]. Available: https://download.geofabrik.de/. [Accessed July 2020].

[28] PERL, J. \& DASKIN, M. S. 1985. A warehouse location-routing problem. Transportation Research Part B: Methodological, 19, 381 396.

[29] RAHMANI, Y., CHERIF-KHETTAF, W. R. \& OULAMARA, A 2015. A Local Search approach for the Two-Echelon Multi-products Location-Routing problem with Pickup and Delivery. IFAC-Papers Online, 48, 193-199.

[30] SAKAI, T., KAZUYA, K. \& TETSURO, H. 2016. Location Choice Models of Urban Logistics Facilities and the Impact of 1 Zoning on their Spatial Distribution and Efficiency. Proceedings of the 95th Annual Meeting of the Transportation Research Board. Washington D.C.

[31] SHEN, L. \& STOPHER, P. R. 2014. Review of GPS Travel Survey and GPS Data-Processing Methods. Transport Reviews, 34, 316-334.

[32] STATISTICS, A. B. O. 2015. 9223.0 - Road Freight Movements, Australia, 12 months ended 31 October 2014 [Online]. Available: https://www.abs.gov.au/ausstats/abs@.nsf/mf/9223.0 [Accessed].

[33] STATISTICS, A. B. O. 2020. Measuring the impacts of COVID-19 [Online].

Available: https://www.abs.gov.au/websitedbs/d3310114.nsf/home/Additional+ ABS+products+to+measure+impact+of+COVID-19 [Accessed].

[34] STEPHAN, K. \& BOYSEN, N. 2011. Cross-docking. Journal of Management Control, 22, 129.

[35] STREETLIGHTDATA. 2020. Streetlight data [Online]. Available: https://www.streetlightdata.com [Accessed 2020].

[36] THILL, J.-C. \& LIM, H. 2010. Intermodal containerized shipping in foreign trade and regional accessibility advantages. Journal of Transport Geography, 18, 530-547.

[37] TSENG, Y., YUE, W. \& TAYLOR, M. Year. The role of transportation in logistics chain in: Proceedings of the Eastern Asia Society for Transportation Studies, Vol 55, pp1657-1672, 2005, 2005.

[38] WYGONIK, E. \& GOODCHILD, A. V. 2018. Urban form and lastmile goods movement: Factors affecting vehicle miles travelled and emissions. Transportation Research Part D: Transport and Environment, 61, 217-229.

[39] YALE, W. H. Year. Data warehouse tools. In: MILCOM 97 MILCOM 97 Proceedings, 3-5 Nov. 1997, 1997. 764-767 vol.2.

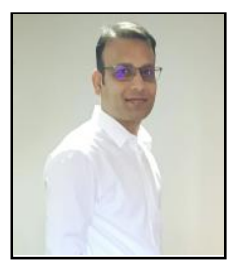

Sushant Siddharth Wanjari is a qualified Mechanical Engineer with post graduate diploma in Management Studies from Tier-I educational institues in India.

He has a rich professional experience in Logistics, Warehousing and Transportation domains of Supply Chain. He has worked for several multinational clients and helped them achieve business transformation goals led by IT. At the time of writing this research paper, he was working as Principal Consultant - Supply chain with DXC Oxygen, Australia.

Mr. Wanjari takes keen interest in the latest innovation in Warehousing and Transportation and he is active members of several supply chain associations. 